\title{
A Cross-Sectional Study: Chest Tube Drainage Practice Patterns among Canadian Thoracic Surgeons Following Pulmonary Surgery
}

\author{
Samarpita Das ${ }^{1}$, Kyle Grant ${ }^{1}$, Connie Drewbrook ${ }^{1}$, Dorsa Mousadoust ${ }^{1}$, Renelle Myers ${ }^{1}$, \\ Basil Nasir'1, John Yee1, Anna McGuire ${ }^{1,2^{*}}$
}

${ }^{1}$ Faculty of Medicine, University of British Columbia, Vancouver, Canada

${ }^{2}$ Division of Thoracic Surgery, Vancouver Coastal Health, Vancouver, Canada

Email: *anna.mcguire@vch.ca

How to cite this paper: Das, S., Grant, K., Drewbrook, C., Mousadoust, D., Myers, R., Nasir, B., Yee, J. and McGuire, A. (2017) A Cross-Sectional Study: Chest Tube Drainage Practice Patterns among Canadian Thoracic Surgeons Following Pulmonary Surgery. Open Journal of Thoracic Surgery, 7, 14-21.

https://doi.org/10.4236/ojts.2017.71003

Received: December 5, 2016

Accepted: March 18, 2017

Published: March 22, 2017

Copyright (c) 2017 by authors and Scientific Research Publishing Inc. This work is licensed under the Creative Commons Attribution International License (CC BY 4.0).

http://creativecommons.org/licenses/by/4.0/

\begin{abstract}
Background: High chest tube drainage following lung surgery is a rate-limiting step to discharge, increasing length of hospital stay. There is a paucity of evidence-based clinical research on safe maximal daily chest tube drainage prior to removal. Objectives: To describe the practice patterns of Canadian thoracic surgeons with respect to daily chest tube drainage after routine pulmonary surgery. Methods: A self-reported electronic questionnaire was administered to members of the Canadian Association of Thoracic Surgeons (CATS). Data was tabulated on the primary outcome of acceptable maximal daily pleural output prior to chest tube removal, and secondary outcomes of: years in clinical practice, academic versus community setting and rational for chest tube management. Descriptive and univariate analysis was conducted for each response by maximal daily pleural drainage category. Results: A total of 124 surveys were distributed. Response rate was $56 \%$, with a $93 \%$ completion rate. Acceptable maximal pleural drainage among surgeons was highly variable. Rationale for tube removal was also variable, including individual clinical experiences $(n=23,33 \%)$, evidence based guidelines $(n=18,26 \%)$, and group practice pattern $(\mathrm{n}=12,17 \%)$. Academic surgeons comprised $72 \%$ of respondents. Community based surgeons were more likely to remove tubes at a lower mean volume. Years in clinical practice did not influence acceptable daily pleural drainage. Conclusion: There is great variability in post-operative management of chest tube fluid output among Canadian thoracic surgeons. Future research on this topic is warranted, with the aim of developing an evidence-based chest tube management algorithm incorporating daily chest tube drainage volumes as a key variable.
\end{abstract}

\section{Keywords}

Thoracic Surgery, Chest Tubes, Oncology, Pleural Cavity 


\section{Background}

Management following routine thoracic surgical procedures such as lobectomy fundamentally relies on minimizing the adverse event of: recurrent pleural effusion, airleak, and empyema-all of which may require chest tube reinsertion [1]-[7]. Persistent air leak and pleural drainage are two mutually exclusive rate-limiting factors for chest tube removal. It is thus imperative to devote separate study to understand these two important aspects of postoperative chest tube management [8]-[19].

Thoracic surgeons discharge patients when air leak is absent, and pleural drainage is below an acceptable level [17]. With respect to air leak management, there are numerous reported "fast-tracking" algorithms fit to appropriate patient scenarios. These have shown to lead to shorter hospitalization, and lower overall costs without compromising standard of care. While prolonged air leak has been thoroughly studied in the context of lung resection, there is yet to be an established gold standard algorithm for management of high volume chest drain output [10] [12] [13]. Daily chest tube drainage greater than 250 milliliters (ml) is a commonly cited reason by surgeons for delayed discharge [11]. This practice may prolong hospital stay on average by two days, and is not evidence based [11] [12]. Increased length of stay can be extrapolated to higher healthcare costs, discomfort for the patient and increased risk of tube-related complications [11] [12] [16] [20].

Although there are no widely accepted evidenced based guidelines for thoracic surgeons to follow with respect to management of high volume chest drain output, protocols with daily volumes ranging from $200 \mathrm{ml}$ to $450 \mathrm{ml}$ have been reported [21]-[29]. Chest tube removal at pleural drainage volumes in excess of $400 \mathrm{ml} /$ day has been studied by Cerfolio et al. In this protocol, chest tube removal at volumes of $450 \mathrm{ml} /$ day was associated with lower rates of indwelling tube duration without increasing the rate of recurrent pleural effusion [4]. In keeping with higher acceptable daily volumes, French et al. suggest that pleural drainage should be assessed as a dynamic parameter in relation to individual body weight, because pleural lymphatic flow is depends on this. A conservative suggestion is that maximal daily pleural drainage should be $15 \%$ of total lymphatic pleural flow [15].

With no generally accepted protocol in place for management of higher volume pleural drainage, this study aims to determine exactly what daily pleural drainage volumes Canadian thoracic surgeons find acceptable to remove a chest tubes following routine lung resection. In order to develop novel chest tube fast-tracking algorithms in the future incorporating daily drainage as a dynamic variable, we must first understand current practice patterns of thoracic surgeons after routine pulmonary resection.

\section{Materials and Methods}

A self-administered electronic questionnaire was sent to all 124 active Canadian Association of Thoracic Surgery (CATS) members using the University of Brit- 
ish Columbia (UBC) electronic survey tool. To maximize response rate and sample size, the questionnaire was administered three times at one-week intervals.

The primary outcome of interested captured was mean acceptable maximal 24-hour pleural drain output prior to chest tube removal. Secondary variables captured included: years in thoracic surgical practice, community versus academic practice setting, average annual number of pulmonary resections, and number and caliber of chest drains placed after routine lobectomy for lung cancer.

Descriptive and univariable analyses were conducted using Stata13 statistical software (StataCorp. 2013. College Station, TX: StataCorp LP). The primary outcome being mean maximal acceptable amount of chest tube drainage observed in the preceding 24 hours, prior to chest tube removal. Categorical data variables examined for their effect on the primary outcome of interest using the Chi square test for association included: years in practice and thoracic surgical practice, rational for chest tube removal algorithm used in clinical practice, and community versus academic practice setting. A two-tailed t-test for association was used for comparison of continuous variables.

\section{Results}

The survey was administered to 124 CATS members. A total of 70 (56\%) surgeons responded, with 65 (93\%) surveys filled to completion. The frequencies of respondent practice characteristics are summarized in Table 1. Maximal acceptable daily pleural drain output prior to removal for the majority was 200 $299 \mathrm{ml}$ or $400-499 \mathrm{ml}(\mathrm{n}=21,30 \%$ for each respectively). The majority of respondents where in thoracic surgical practice for over 20 years $(n=21,30 \%)$, with an academic clinical setting $(\mathrm{n}=51,73 \%)$, and leave one 28 French chest drain after routine pulmonary lobectomy for lung cancer $(n=44,63 \%)$.

When comparing acceptable daily pleural drainage by practice setting, the majority of academic surgeons removed tubes closer to $400 \mathrm{ml}$. Community-based surgeons tended towards lower drainage amounts of $200 \mathrm{ml}$ daily. As summarized in Table 2 , there was very strong evidence $(p=0.0005)$ that Canadian thoracic surgeons in academic practice settings are more likely to remove chest tubes with higher mean daily output compared to community thoracic surgeons.

The analysis for thoracic surgeon characteristics associated with chest tube removal with high daily output $(>400 \mathrm{ml})$ is summarized in Table 3 . There was strong evidence of an association between chest tube removal with high daily output $(>400 \mathrm{ml})$ and the reported algorithm rationale $(\mathrm{p}=0.002)$, and academic practice setting $(\mathrm{p}=0.002)$. There was no evidence of association of years in practice with chest tube removal at higher daily output $(p=0.255)$.

\section{Discussion}

\section{Variability in Practice Patterns:}

The findings of the current study illustrate the wide variability in practice patterns of Canadian thoracic surgeons with respect to acceptable maximal daily 
Table 1. Chest tube practice characteristics after routine pulmonary resection for thoracic surgeon respondents.

\begin{tabular}{|c|c|c|}
\hline & & $\mathrm{n}(\%)$ \\
\hline Variable & & $70(100)$ \\
\hline \multirow{6}{*}{ Maximal acceptable daily pleural drain output prior to removal (ml) } & $<200$ & $5(7.14)$ \\
\hline & $200-299$ & $21(30.0)$ \\
\hline & $300-399$ & $16(22.86)$ \\
\hline & $400-499$ & $21(30.0)$ \\
\hline & $>500$ & $4(5.71)$ \\
\hline & Missing & $3(4.29)$ \\
\hline \multirow{3}{*}{ Pleural drain removal $>400 \mathrm{ml} / 24$ hours } & $<400$ & $42(60.0)$ \\
\hline & $>400$ & $25(35.71)$ \\
\hline & Missing & $3(4.29)$ \\
\hline \multirow{5}{*}{ Rational pleural drain removal algorithm used in clinical practice } & Algorithm from thoracic training & $15(21.43)$ \\
\hline & Individual experience based algorithm & $23(32.86)$ \\
\hline & Evidence based algorithm & $18(25.71)$ \\
\hline & Group practice based algorithm & $12(17.14)$ \\
\hline & Missing & $2(2.86)$ \\
\hline \multirow{6}{*}{ Pleural drains left after routine pulmonary lobectomy } & One 28 French & $44(62.86)$ \\
\hline & Two 28 French & $15(21.43)$ \\
\hline & One 28 French, and One 14 French & $6(8.57)$ \\
\hline & One 24 French & $2(2.86)$ \\
\hline & One 14 French & $1(1.43)$ \\
\hline & Missing & $2(2.86)$ \\
\hline \multirow{5}{*}{ Years in thoracic surgical practice } & Still in Thoracic Training & $7(10.0)$ \\
\hline & $1-5$ years & $13(18.57)$ \\
\hline & $6-10$ years & $12(17.14)$ \\
\hline & $11-20$ years & $17(24.29)$ \\
\hline & $21+$ years & $21(30.0)$ \\
\hline \multirow{2}{*}{ Practice type } & Academic $^{*}$ & $51(72.86)$ \\
\hline & Community & $19(27.14)$ \\
\hline
\end{tabular}

*University academic appointment required as an employment condition. $\mathrm{ml}=$ milliliters.

Table 2. Thoracic surgeon respondent mean acceptable daily chest tube output prior to removal after routine pulmonary resection.

\begin{tabular}{cccc}
\hline \multicolumn{2}{c}{ Max daily drain output $(\mathrm{ml})$} & Mean $(\mathrm{SD})^{\star *}$ & $\mathrm{P}=$ value $^{*}$ \\
\hline \multirow{2}{*}{ Practice type } & Academic & $334.3(14.82)$ & 0.0005 \\
& community & $229.4(23.11)$ & \\
\hline
\end{tabular}

${ }^{*}$ Two tailed T-test for continuous variables. ${ }^{*}$ Mean 24 hour chest tube output prior to chest tube removal after routine lobectomy for academic versus community thoracic surgeons. $\mathrm{SD}=$ standard deviation. $\mathrm{ml}=$ milliliters.

chest tube drainage volume prior to removal. Reasons for the observed practice variability are likely multifactorial, influenced by the surrounding clinical practice environment and biases "learned" in thoracic surgical training. The practice environment and clinical culture may impact ease of access to the limited evidence based literature of the topic of pleural drainage. Prevailing attitudes and "surgical dogma" that the nature of chest tube management postoperatively is a generally mundane and routine topic may also make thoughtful inquiry less likely [11] [12]. 
Table 3. Thoracic surgeon respondent characteristics by low ( $<400 \mathrm{ml} /$ day) versus high $(<400 \mathrm{ml} /$ day $)$ pleural drain output after routine pulmonary resection.

\begin{tabular}{|c|c|c|c|c|}
\hline Variable & & $\begin{array}{c}\text { Low output }<400 \\
\mathrm{ml} / 24 \mathrm{~h} \mathrm{n}(\%)\end{array}$ & $\begin{array}{c}\text { High output }>400 \\
\mathrm{ml} / 24 \mathrm{~h} \mathrm{n}(\%)\end{array}$ & P-value* \\
\hline \multirow{4}{*}{$\begin{array}{c}\text { Rational pleural } \\
\text { drain removal algorithm: }\end{array}$} & Training & $12(29.3)$ & $3(12.0)$ & \multirow{4}{*}{0.002} \\
\hline & Individual & $17(41.5)$ & $5(20.0)$ & \\
\hline & $\mathrm{EBM}$ & $4(9.76)$ & $13(52.0)$ & \\
\hline & Group & $8(19.51)$ & $4(16.0)$ & \\
\hline \multirow{2}{*}{ Practice type } & Academic $^{* *}$ & $26(61.9)$ & $24(96.0)$ & \multirow{2}{*}{0.002} \\
\hline & Community & $16(38.1)$ & $1(4.0)$ & \\
\hline \multirow{5}{*}{ Years in practice } & Training & $3(7.1)$ & $4(16.0)$ & \multirow{5}{*}{0.255} \\
\hline & 1 - 5 years & $7(16.7)$ & $5(20.0)$ & \\
\hline & $6-10$ years & $9(21.4)$ & $3(12.0)$ & \\
\hline & $11-20$ years & $7(16.7)$ & $8(32.0)$ & \\
\hline & $21+$ years & $16(38.1)$ & $5(20.0)$ & \\
\hline
\end{tabular}

${ }^{*}$ Chi-square test of association. ${ }^{*}$ University academic appointment required as an employment condition. $\mathrm{ml}=$ milliliters $. \mathrm{EBM}=$ evidence based medicine.

\section{Evidence Based Practice and Daily Chest Tube Drainage:}

Despite the large amount of prospective data surrounding chest tube management in the context of air leak, there is only one large prospective study, conducted by Cerfolio et al., that incorporates higher volume output into chest tube removal algorithms without increased patient morbidity [12]. When examining rationale behind acceptable daily pleural drainage in the current study, although heterogeneous acceptable volumes were reported, those who stated they followed evidenced based guidelines were more likely to remove chest tubes with higher daily output (400 ml-daily). It thus appears several respondents are referring to Cerfolio's study to guide evidence based clinical practice.

Despite literature on the safety of chest tube removal after lobectomy with output volumes of $400 \mathrm{ml}$ daily, our study suggests evidence of persistent dogmatic attitudes guiding chest tube practice patterns in Canada. The highest respondent reported frequency for rationale guiding practice pattern was "individual experience" ( $\mathrm{n}=23,33 \%)$. This is consistent with a recent large American surgeon survey conducted by Kim et al. [30]. They examined practice patterns among American surgeons using the Society of Thoracic Surgeons database. Our studies reveal consistent results in that surgeons in an academic clinical setting were more likely to remove chest tubes with higher daily output volumes compared to community surgeons.

\section{Study Limitations}

The overwhelming majority of respondents in this study were academic practice based thoracic surgeons. Information bias in the form of response bias may thus be present, with community thoracic surgeons under-represented. Academic institutions with thoracic surgical residency training programs, regular teaching rounds, and activities such as journal club discussion may be more likely to be aware of most current literature given the environment supported.

Selection bias may also be present based on our sampling method. The study sample was drawn from the CATS roster membership list. This roster may not 
encompass Canada-wide practices, as it only includes thoracic surgeons who have self-selected to be CATS members. If these surgeons are in some way systematically different from non-members, it would make study findings difficult to generalize.

\section{Conclusions}

There is significant practice variability among Canadian thoracic surgeons with respect to acceptable chest tube drainage volumes following routine pulmonary resection prior to tube removal. Many Canadian surgeons appear to use evidence based literature to guide their chest tube management decisions, however practice based on individual experiences and surgical "dogma" remains. Thoracic surgeons practicing at academic centers were more likely to remove chest tubes at higher mean daily drainage volumes compared to those in community practice.

Future study on this topic is warranted in the context of developing and implementing post-operative pulmonary chest tube management algorithms that include higher mean daily volumes. Such "fast-track" chest tube management algorithms are an important tool to ensure austerity and promote economic sustainability in the Canadian single-payer health care setting.

\section{References}

[1] Abolhoda, A., Liu, D., Brooks, A. and Burt, M. (1998) Prolonged Air Leak Following Radical Upper Lobectomy. Chest, 113, 1507-1510.

https://doi.org/10.1378/chest.113.6.1507

[2] Antanavicius, G., Lamb, J., Papasavas, P. and Caushaj, P. (2005) Initial Chest Tube Management after Pulmonary Resection. American Surgeon, 71, 416-419.

[3] Belda-Sanchís, J., Serra-Mitjans, M., Sentis, M.I. and Rami, R. (2010) Surgical Sealant for Preventing Air Leaks after Pulmonary Resections in Patients with Lung Cancer. Cochrane Database of Systematic Reviews Review.

[4] Bertholet, J.W.M., Joosten, J.J.A., Keemers-Gels, M.E., Vanden Wildenberg, F.J.H. and Barendregt, W.B. (2011) Chest Tube Management following Pulmonary Lobectomy: Change of Protocol Results in Fewer Air Leaks. Interactive Cardio Vascular and Thoracic Surgery, 12, 28-31. https://doi.org/10.1510/icvts.2010.248716

[5] Brunelli, A., Monteverde, M., Borri, A., Salati, M., Marasco, R.D., Al Refai, M. and Fianchini, A. (2004) Comparison of Water Seal and Suction after Pulmonary Lobectomy: A Prospective, Randomized Trial. The Annals of Thoracic Surgery, 77, 1932-1937.

[6] Brunelli, A., Monteverde, M., Borri, A., Salati, M., Marasco, R.D. and Fianchini, A. (2004) Predictors of Prolonged Air Leak after Pulmonary Lobectomy. The Annals of Thoracic Surgery, 77, 1205-1210.

[7] Cafarotti, S., Cusumano, G., Giuliani, M., Matarelli, E., Carboni, G.L., Schneiter, D., Pneumoclub Tichino, C.H. and Dutly, A.E. (2015) Extra-anatomical VATS Lung Resection: The Outpatient Experience with the Aid of a Digital Chest Drain Device. European Review for Medical and Pharmacological Sciences, 19, 3850-3854.

[8] Cerfolio, R.J., Bass, C. and Katholi, C.R. (2001) Prospective Randomized Trial Compares Suction versus Water Seal for Air Leaks. The Annals of Thoracic Surgery, 71, 1613-1617. https://doi.org/10.1016/S0003-4975(01)02474-2 
[9] Cerfolio, R.J., Bass, C.S., Pask, A.H. and Katholi, C.R. (2002) Predictors and Treatment of Persistent Air Leaks. The Annals of Thoracic Surgery, 73, 1727-1731. https://doi.org/10.1016/S0003-4975(02)03531-2

[10] Cerfolio, R.J. (2002) Chest Tube Management after Pulmonary Resection. Chest Surgery Clinics of North America, 12, 507-527. https://doi.org/10.1016/S1052-3359(02)00015-7

[11] Cerfolio, R.J. and Bryant, A.S. (2008) The Benefits of Continuous and Digital Air Leak Assessment after Elective Pulmonary Resection: A Prospective Study. The Annals of Thoracic Surgery, 86, 396-401. https://doi.org/10.1016/j.athoracsur.2008.04.016

[12] Cerfolio, R.J. and Bryant, A.S. (2008) Results of a Prospective Algorithm to Remove Chest Tubes after Pulmonary Resection with High Output. The Journal of Thoracic and Cardiovascular Surgery, 135, 269-273. https://doi.org/10.1016/j.jtcvs.2007.08.066

[13] Coughlin, S., Emmerton-Coughlin, H. and Malthaner, R. (2012) Management of Chest Tubes after Pulmonary Resection: A Systematic Review and Meta-Analysis. Canadian Journal of Surgery, 55, 264-270. https://doi.org/10.1503/cjs.001411

[14] Filosso, P.L., Nigra, V.A., Lanza, G., Costardi, L., Bora, G., Solidoro, P., Cristofori, R.C., Molinatti, M., Lausi, P.O., Ruffini, E., Oliaro, A. and Guerrera, F. (2015) Digital versus Traditional Air Leak Evaluation after Elective Pulmonary Resection: A Prospective and Comparative Mono-Institutional Study. Journal of Thoracic Disease, 7, 1719-1724.

[15] French, D.G., Dilena, M., LaPlante, S., Shamji, F., Sundaresan, S., Villeneuve, J., Seely, A., Maziak, D. and Gilbert, S. (2016) Optimizing Postoperative Care Protocols in Thoracic Surgery: Best Evidence and New Technology. Journal of Thoracic Disease, 8, S3-S11.

[16] Kwiatt, M., Tarbox, A., Seamon, M., Swaroop, M., Cipolla, J., Allen, C., StacinoelHallenbeck, H., Davido, T., Lindsey, D., Doraiswamy, V., Galwankar, S., Tulman, D., Latchana, N., Papadimos, T.J, Cook, C.H. and Stawicki, S.P. (2014) Thoracostomy Tubes: A Comprehensive Review of Complications and Related Topics. International Journal of Critical Illness and Injury Science, 4, 142-155. https://doi.org/10.4103/2229-5151.134182

[17] Lang, P., Manickavasagar, M., Burdett, C., Treasure, T. and Fiorentino, F. (2015) Suction on Chest Drains following Lung Resection: Evidence and Practice Are Not Aligned. European Journal of Cardio-Thoracic Surgery, 49, 611-616. https://doi.org/10.1093/ejcts/ezv133

[18] Lee, L., Hanley, S.C., Robineau, C., Sirois, C., Mulder, D.S. and Ferri, L.E. (2011) Estimating the Risk of Prolonged Air Leak after Pulmonary Resection Using a Simple Scoring System. Journal of the American College of Surgeons, 212, 1027-1032. https://doi.org/10.1016/j.jamcollsurg.2011.03.010

[19] Marshall, M.B., Deeb, M.E., Bleier, J.I.S., Kucharczuk, J.C., Friedberg, J.S., Kaiser, L.R. and Shrager, J.B. (2002) Suction vs Water Seal after Pulmonary Resection. Chest, 121, 831-835. https://doi.org/10.1378/chest.121.3.831

[20] Martino, K., Merrit, S., Boyakye, K., Sernas, T., Koller, C., Hauser, C.J., Lavery, R. and Livingston, D.H. (1999) Prospective Randomized Trial of Thoracostomy Removal Algorithms. The Journal of Trauma: Injury, Infection, and Critical Care, 46, 369-373. https://doi.org/10.1097/00005373-199903000-00003

[21] Mueller, M.R. and Marzluf, B.A. (2014) The Anticipation and Management of Air Leaks and Residual Spaces Post Lung Resection. Journal of Thoracic Disease, 6, 271-284. 
[22] Refai, M., Brunelli, A., Varela, G., Novoa, N., Pompili, C., Jimenez, M.F., Aranda, J.L. and Sabbatini, A. (2012) The Values of Intrapleural Pressure before the Removal of Chest Tube in Non-complicated Pulmonary Lobectomies. European Journal of Cardio-Thoracic Surgery, 41, 831-833. https://doi.org/10.1093/ejcts/ezr056

[23] Rivera, C., Bernard, A., Falcoz, P., Thomas, P., Schmidt, A., Bénard, S., Vicaut, E. and Dahan, M. (2011) Characterization and Prediction of Prolonged Air Leak after Pulmonary Resection: A Nationwide Study Setting up the Index of Prolonged Air Leak. The Annals of Thoracic Surgery, 92, 1062-1068.

https://doi.org/10.1016/j.athoracsur.2011.04.033

[24] Royer, A.M., Smith, J.S., Miller, A., Spiva, M., Holcombe, J.M. and Headrick, J.R. (2015) Safety of Outpatient Chest Tube Management of Air Leaks after Pulmonary Resection. American Surgeon, 81, 760-763.

[25] Steéphan, F., Boucheseiche, S., Hollande, J., Flahault, A., Cheffi, A., Bazelly, B. and Bonnet, F. (2000) Pulmonary Complications Following Lung Resection. Chest, 118, 1263-1270. https://doi.org/10.1378/chest.118.5.1263

[26] Utter, G.H. (2013) The Rate of Pleural Fluid Drainage as a Criterion For the Timing of Chest Tube Removal: Theoretical and Practical Considerations. The Annals of Thoracic Surgery, 96, 2262-2267. https://doi.org/10.1016/j.athoracsur.2013.07.055

[27] Varela, G., Jiménez, M. and Novoa, N. (2010) Portable Chest Drainage Systems and Outpatient Chest Tube Management. Thoracic Surgery Clinics, 20, 421-426. https://doi.org/10.1016/j.thorsurg.2010.03.006

[28] Younes, R.N., Gross, J.L., Aguiar, S., Haddad, F.J. and Deheinzelin, D. (2002) When to Remove a Chest Tube? Journal of the American College of Surgeons, 195, 658-662. https://doi.org/10.1016/S1072-7515(02)01332-7

[29] Tang, A., Hooper, T. and Hasan, R. (1999) A Regional Survey of Chest Drains: Evidence-Based Practice? Postgraduate Medical Journal, 75, 471-474. https://doi.org/10.1136/pgmj.75.886.471

[30] Kim, S.S., Khalpey, Z., Daugherty, S.L., Torabi, M. and Little, A.G. (2016) Factors in the Selection and Management of Chest Tubes after Pulmonary Lobectomy: Results of a National Survey of Thoracic Surgeons. The Annals of Thoracic Surgery, 101, 1082-1088. https://doi.org/10.1016/j.athoracsur.2015.09.079

\section{Scientific Research Publishing}

\section{Submit or recommend next manuscript to SCIRP and we will provide best service for you:}

Accepting pre-submission inquiries through Email, Facebook, LinkedIn, Twitter, etc. A wide selection of journals (inclusive of 9 subjects, more than 200 journals)

Providing 24-hour high-quality service

User-friendly online submission system

Fair and swift peer-review system

Efficient typesetting and proofreading procedure

Display of the result of downloads and visits, as well as the number of cited articles

Maximum dissemination of your research work

Submit your manuscript at: http://papersubmission.scirp.org/

Orcontact ojts@scirp.org 